\title{
Fluorescent dot peen marking for insuring oil steel pipes traceability
}

\author{
Aleksey Lezhnev ${ }^{1, *}$, Yuliya Prikina $^{2}$, Alexander Roschin ${ }^{3}$, and Aisalkyn Choboeva ${ }^{3}$ \\ ${ }^{1}$ LLC "VKO "Simvol”, Chief executive officer, 105120 Moscow, Syromyatnichesky drive 6-1, Russia \\ ${ }^{2}$ LLC "TMK NTC", Head of the laboratory, 143026 Moscow Skolkovo Community, Russia \\ ${ }^{3}$ LLC "VKO "Simvol", chemical laboratory, 105120 Moscow, Syromyatnichesky drive 6-1, Russia
}

\begin{abstract}
VKO "Simvol" designs and produces marking equipment, reading equipment and traceability software. Fluorescent dot-peen marking (FDMP) is an improved version of dot peen marking (DPM) technology. In FDPM technology information dots are filled with special material - fluorescent composition. Various fluorescent compositions provide high stability of marking in different aggressive media, such as moisture, salt and acid solutions, oils, lubricants or high temperatures. 2D barcode Data Matrix makes the marking machine readable, even if some of the dots are damaged.
\end{abstract}

\section{Introduction}

Oil steel pipes (further - pipes) pass many operations and technological processes during their lifetime transportation, storage, working in the aggressive media, repair, and disposal. An objective of identification and administrating each pipe's "individual story" during all stages of its life cycle is quite relevant for oil industry.

Manufacturer marking for oil and gas pipes contains product description and all the information for pipes identification. This marking serves to the pipe manufacturer's purposes only, while oil and gas companies needs stay unsatisfied in case of the information loss.

Identification (individual pipe recognition) requires availability of sustainable identification signs during any operations with the pipe. Marking is the most common way of identification. Machine-readable marking (further - marking), which helps to trace the entire product's life cycle, is used in modern automated systems.

Pipe traceability provision has a number of features related to the marking's sustainability to various types of mechanic, climate and chemical or media impacts during manufacture, transportation, storage, operation and repair. Therefore there is need for modern methods of marking that are resistant to aggressive environment [1]. Since exposure in oil and gas environment (high pressure, high temperature, $\mathrm{CO}_{2}$ and $\mathrm{H}_{2} \mathrm{~S}$ content) during the operation of pipe or tube causes destruction of equipment [2 -4].

The aim of this study to ability to survive fluorescent dot peen marking (FDPM) the severe tests, modelling the conditions of oil and gas industry.

\section{FDPM reading}

Fluorescence of the information dots in FDPM provides better contrast than usual DPM marking. When reading FDPM, the machine records only the fluorescence of the dots, information elements (Fig. 1). The surface of a marked product and its optical properties have minimal influence on FDPM reading, and. This allows to reduce the influence of marked surface brightness, its curvilinear profile, the color of the coatings, rust, roughness during reading FDPM. In case of damage, FDPM can be recovered.

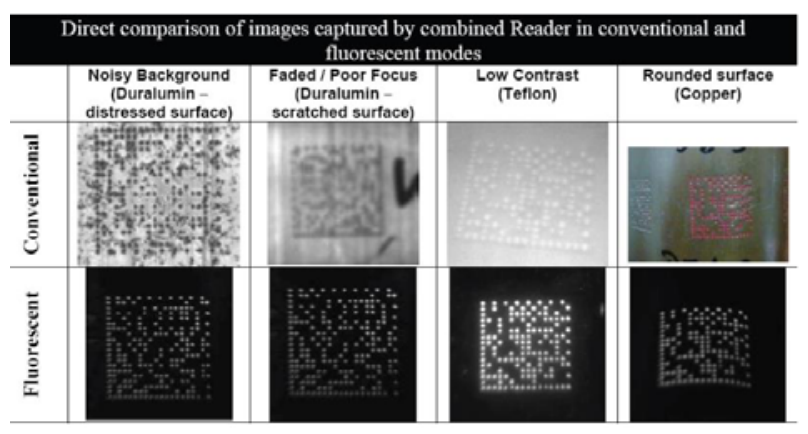

Fig. 1. DPM (top) vs FDPM (bottom) reading.

\section{FDPM stability in aggressive media}

Various types of polymer compositions and fluorescent dyes application makes it possible to create FDPM with high resistance to various environments, such as:

- Demineralized water;

- Moisture media (Fig. 2), >45 days;

- Sea water, $>2000$ hours;

- 3\% saline solution $(\mathrm{NaCl}),>720$ hours;

\footnotetext{
* Corresponding author: a.lezhnev@,vko-simvol.ru
} 
- Detergents, both acidic and alkaline, $>720$ hours;

- 3\% hydrochloric acid ( $\mathrm{HCl}),>720$ hours;

- Petrol, oil and lubricants - engine oil, >16 months;

- Petrol, >5400 hours;

Furthermore, FDPM is resistant to:

- High pressure;

- Ionizing radiation;

- High temperatures $\left(1,000{ }^{\circ} \mathrm{C}\right.$ - up to 22 hours, $600{ }^{\circ} \mathrm{C}$ - more than 200 hours);

- Temperature variations from plus $60{ }^{0} \mathrm{C}$ to minus $60{ }^{0} \mathrm{C}$ over 180 cycles;

- Mechanical impact (10 hammer strokes; abrasive treatment).

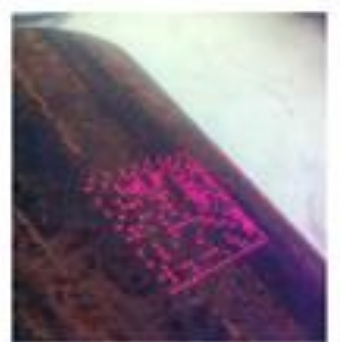

\section{FDPM}

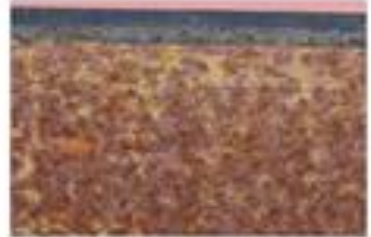

DPM
Fig. 2. Comparison of FDPM and DPM after the ASTM D 870-02 moisture resistance tests, 45 days exposure.

FDPM can survive intensive mechanical treatment, which used for paint and corrosion removing from the surface. Photo of FDPM on a steel pipe after shot blasting is shown on Fig. 3.

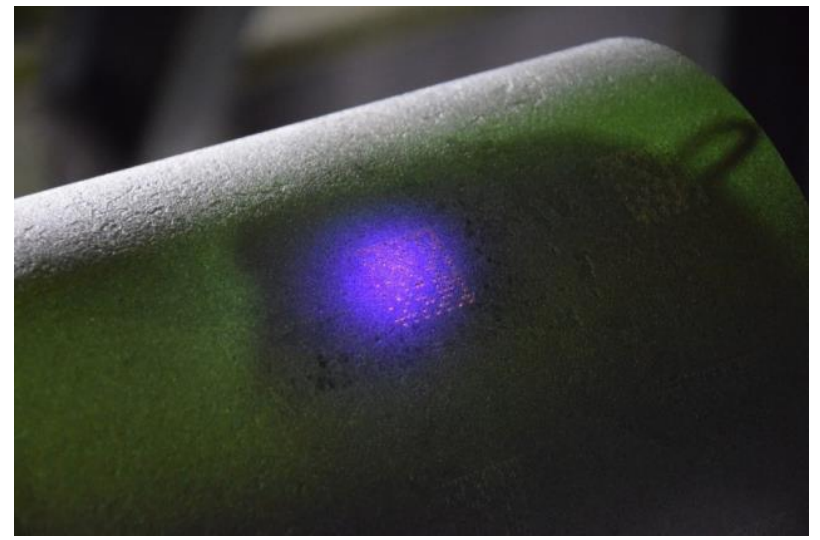

Fig. 3. FDPM on a steel pipe after shot blasting, photo in fluorescent light.

The high contrast and stability allow to read FDPM after transporting, mounting and operating oil pipes. The photo on Fig. 4 shows fluorescence of FDPM dots on the pipe after high temperature and shot-blasting treatment, the marking remains readable.

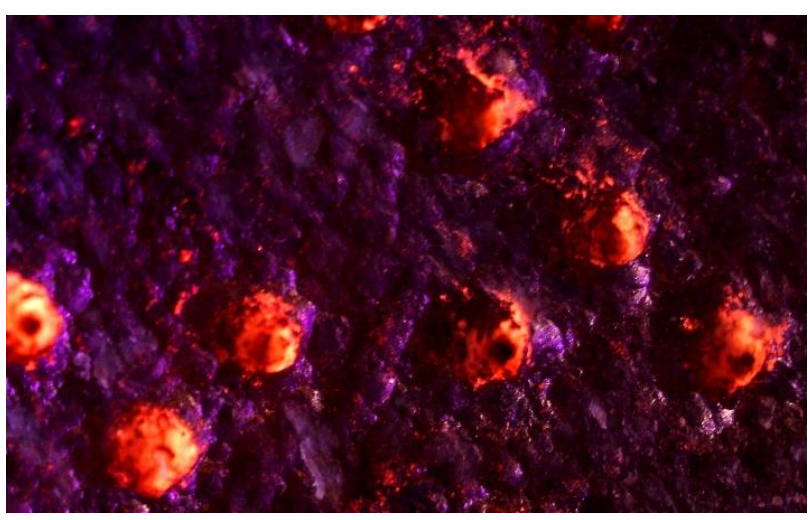

Fig. 4. Micro photo of FDPM on the pipe after thermal and shot blasting, application and removal of the protective coating with heat shrink tape.

The developer patented a number of processes, devices and compositions used in his hardware and technology complex, which provides for the application of FDPM, their reading and use for building an automated system of product identification and traceability. Patent list is given in the Literature section [5 - 13].

The effect of marking on the mechanical and corrosion properties of pipe and tube material has been studied by several researchers [14]. The requirements for resistance to aggressive media must be applied for FDPM.

It was performed a set of FDPM stability tests on pipe samples. The samples were tested in environments, modelling climate conditions and oil pipe operating media. Tests with 11 different fluorescence compositions were performed, this allowed to find the most persistent compositions.

In high-pressure corrosive media primary corrosion products (rust) were formed on the surface of the samples during testing. Fig. 5 gives an example of the marking before and after the test in the simulating oil well conditions: $5 \% \mathrm{NaCl}$ solution $\mathrm{P}=(1,0 \pm 0,5) \mathrm{MPa}$, $\mathrm{p}\left(\mathrm{CO}_{2}\right)=(1,0 \pm 0,5) \mathrm{MPa}, \mathrm{t}=(120 \pm 3){ }^{\circ} \mathrm{C}$ for 24 hours. FDPM was readable after the mechanical removing the corrosion products.
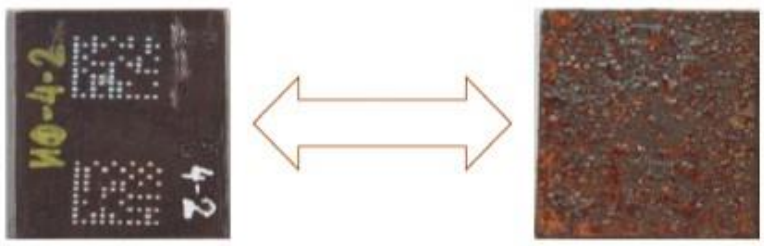

Fig. 5. Fluorescent dot-peen marking before (left) and after (right) tests for 24 hours in $5 \%$ solution $\mathrm{NaCl}$ at total pressure $(1,0 \pm 0,5) \mathrm{MPa}$ and partial pressure $\mathrm{CO}_{2}(1,0 \pm 0,5) \mathrm{MPa}$; temperature $(120 \pm 3){ }^{\circ} \mathrm{C}$. Corrosion products are not removed.

Test results of the best FDPM fluorescent compositions for pipes are shown in Table 1. 
Table 1. Reading FDPM with several fluorescent compositions after aggressive environments tests. "+" - readable, "-" unreadable, the “*” sign means corrosion products removal.

\begin{tabular}{|c|c|c|}
\hline Test environment & $\begin{array}{l}\text { Fluorescent } \\
\text { composition } \\
\text { code and } \\
\text { sample } \\
\text { number }\end{array}$ & $\begin{array}{l}\text { FDPM } \\
\text { reading } \\
\text { results }\end{array}$ \\
\hline \multicolumn{3}{|c|}{ Climatic factors } \\
\hline \multirow{2}{*}{$\begin{array}{l}\text { Temperature minus }(60 \pm 3) \\
\text { to plus }(60 \pm 3), 15 \text { cycles }\end{array}$} & KJ-55 & + \\
\hline & KL-56 & + \\
\hline \multirow{4}{*}{$\begin{array}{l}\text { Variable temperature, } \\
\text { elevated humidity and solar } \\
\text { radiation according to GOST } \\
9.401, \text { method } 4\end{array}$} & KL-54-1 & - \\
\hline & KJ-53-1 & - \\
\hline & KL-54-2 & $+*$ \\
\hline & KJ-53-2 & $+*$ \\
\hline \multicolumn{3}{|c|}{ Operating factors } \\
\hline \multirow{3}{*}{$\begin{array}{l}\text { Acid composition } \\
\left(\mathrm{T}=20 \pm 3{ }^{\circ} \mathrm{C}\right), 24 \text { hours: } \\
\text { - } \mathrm{HCl}-12 \% \text {, } \\
\text { - corrosion inhibitor }-0,5 \% \text {; } \\
\text { - iron stabilizer }-1 \% \text {; } \\
\text { - demulsifier }-1 \% \text {. }\end{array}$} & KJ-3 & + \\
\hline & $\mathrm{KJ}-4$ & + \\
\hline & KL-50 & + \\
\hline \multirow{3}{*}{$\begin{array}{l}\mathrm{NaCl} 5 \%\left(\mathrm{~T}=80 \pm 3{ }^{\circ} \mathrm{C}\right), 240 \\
\text { hours, partial pressure } \mathrm{CO}_{2} \\
(1,0 \pm 0,5) \mathrm{MPa} \text {, total } \\
\text { autoclave pressure }(5,0 \pm 0,5) \\
\mathrm{MPa}\end{array}$} & KL-5 & + \\
\hline & KL-6 & + \\
\hline & KJ-59 & + \\
\hline \multirow{4}{*}{$\begin{array}{l}\mathrm{NaCl} 5 \%\left(\mathrm{~T}=120 \pm 3{ }^{\circ} \mathrm{C}\right), 24 \\
\text { hours, partial pressure } \mathrm{CO}_{2} \\
(1,0 \pm 0,5) \mathrm{MPa} \text {, total } \\
\text { autoclave pressure }(1,0 \pm 0,5) \\
\mathrm{MPa}\end{array}$} & KJ-51-1 & - \\
\hline & KL-52-1 & - \\
\hline & KJ-51-2 & $+*$ \\
\hline & KL-52-2 & $+*$ \\
\hline \multirow{2}{*}{ Shot blasting } & KL-57 & + \\
\hline & KJ-58 & + \\
\hline
\end{tabular}

\section{Conclusion}

The results show the FDPM ability to survive the severe tests, modelling the conditions of oil pipe lifetime. Although most of the compositions tested did not show acceptable stability, some of them showed good reading results and should be developed further. According to the results of the laboratory experiments, FDPM based on composition «K» and luminophore « $\langle$ J» was recommended to test on pump-compressor pipes and oil and gas pipes in pilot industrial operation.

\section{References}

1. M. Sambasivan, S. Gopal, Handbook of Oil and Gas Piping: a Practical and Comprehensive Guide (CRC Press, London, 2018)

2. R. Heidersbach. Metallurgy and Corrosion Control in Oil and Gas Production (John Wiley \& Sons, Inc., 2010)

3. L. Popoola, A.Grema, G.Kayode et.al., Corrosion problems during oil and gas production and its mitigation (International Journal of Industrial Chemistry, 4:35, 2013)

4. I. Kostitsyna, A. Shakhmatov, A. Davydov, Study of corrosion behavior of carbon and low-alloy steels in $\mathrm{CO}_{2}$-containing environments (E3S Web Conf., 121, 04006, 2019)

5. Patent of the Russian Federation on invention № 2490709, "Fluorescent informational label and methods of its manufacture." A.V. Lezhnev, M.U. Kvasha, G.N. Dorozhkina, K.I. Donetskiy

6. Patent of the Russian Federation on invention № 2538580 "Polymer composition, direct applicationc marking with polymer composition manufacture method and direct application marking." A.E. Zhedulov, A.V. Lezhnev, A.L. Roschin, G.N. Dorozhkina

7. Patent of the Russian Federation on invention № 2550179 "Polymer composition, direct part marking with polymer composition manufacture method and direct application marking." A.E. Zhedulov, A.V. Lezhnev, A.L. Roschin, G.N. Dorozhkina

8. Patent of the Russian Federation on invention № 2598290 “A method for monitoring controlled parameters in multiple local areas using labels." M.U. Kvasha, V.V. Gutenev, A.L. Roschin, A.V. Lezhnev, G.N. Dorozhkina, I.E. Diskin

9. Patent of the Russian Federation on invention № 2609912 "A method for producing, including restoring, fluorescent direct application marking." M.U. Kvasha, A.L. Roschin, A.V. Lezhnev, G.N. Dorozhkina, O.V. Holkin, A.E. Zheludov

10. Patent of the Russian Federation on invention № 2634829 “A method for protecting, including renewable, the marking of direct application against external influences and unauthorized reading" M.U. Kvasha, A.L. Roschin, A.V. Lezhnev, G.N. Dorozhkina, O.V. Holkin, A.E. Zheludov

11. Patent of the Russian Federation on invention № 2637041 “A method for producing direct applying marking” M.U. Kvasha, A.L. Roschin, A.V. Lezhnev, G.N. Dorozhkina, O.V. Holkin

12. Patent of the Russian Federation on invention № 2665867 "Machine readable microrelief direct application marking" A.V. Lezhnev, A.L. Roschin, A.K. Choboeva

13. Patent of the Russian Federation on invention № 2715462 "Method of marking application” A.V. Lezhnev, O.A. Omarov, S.A. Pavlov, A.L. Roschin

14. F. Alavi, E. Homagerani, M. Rasooly, Standardization of laser marking for tracking gas pipes in transmission and distribution projects by destructive and nondestructive tests, (12th European Conference on Non-Destructive Testing (ECNDT 2018), Gothenburg 2018, June 11-15 (ECNDT 2018)) 